\title{
Construction of the First Certification Evaluation Index System for Diabetes Specialist Nurses by Delphi Method
}

\author{
Haihua Zou ${ }^{1}$, Xue Gong ${ }^{1 *}$, Siyun Wang ${ }^{2}$, Weiju Chen ${ }^{1 \#}$ \\ ${ }^{1}$ Nursing Department, The First Affiliated Hospital of Jinan University, Guangzhou, China \\ ${ }^{2}$ Nursing School, Sichuan College of Traditional Chinese Medicine, Mianyang, China \\ Email: "313761095@qq.com
}

How to cite this paper: Zou, H.H., Gong, X., Wang, S.Y. and Chen, W.J. (2020) Construction of the First Certification Evaluation Index System for Diabetes Specialist Nurses by Delphi Method. International Journal of Clinical Medicine, 11, 242-251. https://doi.org/10.4236/ijcm.2020.115025

Received: April 15, 2020

Accepted: May 10, 2020

Published: May 13, 2020

Copyright $\odot 2020$ by author(s) and Scientific Research Publishing Inc. This work is licensed under the Creative Commons Attribution International License (CC BY 4.0).

http://creativecommons.org/licenses/by/4.0/

\begin{abstract}
Objective: To establish an evaluation index system for the first-time certification of diabetes specialist nurses in line with the clinical nursing practice in China, and to provide a reference basis for government administrations and hospitals to formulate unified standards. Methods: After the research team has determined the theme, it will consult the development of A) specialist nursing through the library, Internet and electronic literature database; B) the history of the development of specialist nurses in diabetes and other fields; C) the selection criteria of specialist nurses; D) the training of specialist nurses system, assessment method; E) Specialist nurse certification body, evaluation standards and certification standards and other related documents, literature, books and report materials. The author established the preliminary index system through literature review, specialist interview and group discussion and used Delphi method to organize three rounds of 30 experts' consultations. Results: A first certification evaluation index system including 8 fundamental indicators, 5 first-level indicators, 19 second-level indicators and 99 third-level indicators was constructed for diabetes nurses. Conclusion: The results of three rounds of expert consultation and demonstration are reliable, and the constructed index system is suitable for comprehensive evaluation of diabetes specialist nurses, which provides a basis for the effective management of nursing resources.
\end{abstract}

\section{Keywords}

Diabetic Specialist Nurses, First Certification Evaluation Index, Delphi Method 


\section{Introduction}

With the development of social economy, the prevalence of diabetes is rising world widely. According to the statistics of the International Diabetes Federation (IDF), it is estimated that 380 million people will be diagnosed with diabetes by 2025 [1]. A survey conducted by the Diabetes Branch of the Chinese Medical Association, published in the New England Journal in March 2010, shows that the number of patients with diabetes in China has exceeded 92 million [2], making it a major diabetic country. In order to cope with the growing population of diabetic patients and the resulting economic and medical burdens, diabetes specialist nurses have been trained throughout the country [3]. However, there is no uniform standard for the selection, training, assessment and certification of diabetes nurses in China so far [4] [5]. In this study, the Delphi method was used to establish an evaluation index for the first certification of diabetes specialist nurses, which is expected to provide a reference basis for the certification of diabetes specialist nurses.

\section{Steps and Methods}

\subsection{Set up a Research Team and Select Consulting Experts}

The research team consisted of 5 people, including 1 director of nursing department, 1 head nurse, and 3 graduate students. 30 clinical experts, involving nursing management, nursing education, clinical nursing, community nursing, medicine, were selected from 10 provinces in East China, South China, West China, North China, and Central China. Every expert is either from Class A First Class Hospital or from college of advanced nursing with the technical title of deputy senior or above (except the experts from clinical nursing, whose minimal title is intermediate level). The experts with bachelor degree or above have more than 10 years of experience in diabetes or related majors.

\subsection{Research Tools}

After the research team has determined the theme, it will consult the development of A) specialist nursing through the library, Internet and electronic literature database; B) the history of the development of specialist nurses in diabetes and other fields; C) the selection criteria of specialist nurses; D) the training of specialist nurses System, assessment method; E) specialist nurse certification body, evaluation standards and certification standards and other related documents, literature, books and report materials. The author established the preliminary index system through literature review, specialist interview and group discussion and used Delphi method to organize three rounds of 30 experts' consultations. Key words of database retrieval include: diabetes specialist nurses, current situation and development of specialist nursing, selection criteria, system specifications, assessment methods, certification bodies, evaluation criteria, etc. Review the collected literature content (see Figure 1 for the selection process of literature data and Table 1 for the selection content). 


\begin{tabular}{|c|c|c|}
\hline $\begin{array}{l}\text { Construction of the first certification evaluation } \\
\text { index system for diabetes specialist nurses }\end{array}$ & & \multirow{4}{*}{$\begin{array}{l}\text { China HowNet, WeiPu } \\
\text { database, MEDLINE, Pub Med } \\
\text { database, Web of science } \\
\text { database, etc. }\end{array}$} \\
\hline$\sqrt{2}$ & \multirow{3}{*}{$\Rightarrow$} & \\
\hline Search library selection & & \\
\hline$\checkmark$ & & \\
\hline Literature selection criteria & \multirow[t]{2}{*}{$\Rightarrow$} & \multirow{2}{*}{$\begin{array}{l}\text { Literature, documents, books, } \\
\text { reports }\end{array}$} \\
\hline$\sqrt{2}$ & & \\
\hline Filter content & \multirow[t]{5}{*}{$\Rightarrow$} & \multirow{5}{*}{$\begin{array}{l}\text { A. Development of specialist nursing } \\
\text { B. History of the development of } \\
\text { diabetes nurses and other nurses } \\
\text { C. Selection criteria for specialist nurses } \\
\text { D. Training system and assessment } \\
\text { method for specialist nurses } \\
\text { E. Specialized nurse certification } \\
\text { institutions, evaluation standards and } \\
\text { certification standards }\end{array}$} \\
\hline$\Omega$ & & \\
\hline $\begin{array}{l}\text { Literature review, expert interviews, } \\
\text { consultations and discussions }\end{array}$ & & \\
\hline 约 & & \\
\hline $\begin{array}{l}\text { Establish an indicator framework and form the } \\
\text { first round of expert consultation questionnaire }\end{array}$ & & \\
\hline
\end{tabular}

Figure 1. Selection process of research materials.

Table 1. Research materials of literature review and selection.

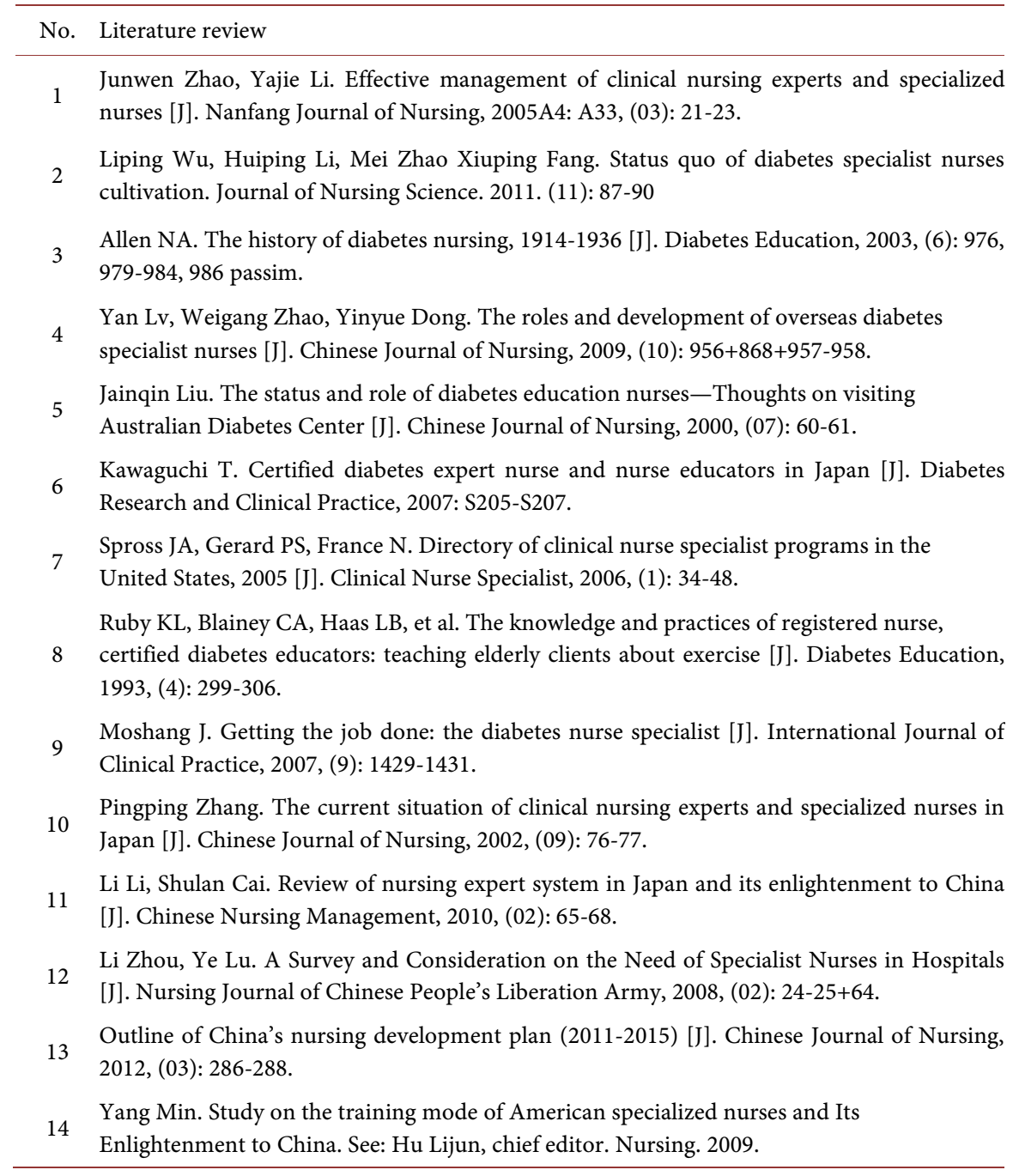




\section{Continued}

15 Huo Xiaorong, Liu Shiqing, Mo Yongzhen. Practice and experience of establishing training base for diabetes specialty nurses [J]. Chinese Journal of Nursing, 2007, (06): 496-498.

Yajie Li, Liyin Zhang, Gangyi Peng, etc. The implementation of advanced course education

16 for graduate students of diabetes specialty nurses in Guangdong Province [J]. Chinese Journal of Nursing, 2007, (06): 499-501.

17 Leishi Chen. Management of nursing professional development in Hong Kong [J]. (Chinese Nursing Management, 2006, (12): 12-15.

18 Xiuhua Li, Jingxia Guo,Chunjuan Xu, etc. A study on the demands and status of the development of specialty nursing [J]. Chinese Nursing Managemen, 2005, (05): 8-12.

19 Huailin Li. "Certification, standards, economy" [M]. Beijing: China Economic Publishing House, 2005.

20 Chunyan Song, Juxiang Wang. Quantitative study of nurse core competency and influence analysis of demographic variables [J]. Chinese Journal of Nursing, 2009, (01): 11-14.

21 Shen Ning. Research Report on teaching reform of nursing major [M]. Beijing: Higher Education Press, 2000: 11-12.

Chen Wei, Ma Shuqin, Mao Xueyi. Appreciation system theory and cognitive learning

22 theory-A comparative analysis of the three principles of system theory and cognitive learning theory [J]. Journal of Lan Zhou Institute of Education, 2013, (06): 103-104.

23 Junwen Zhao, Yajie Li. Effective management of clinical nursing experts and specialized nurses [J]. Nanfang Journal of Nursing, 2005, (03): 21-23.

24 Ruihua Jin, Jie Zheng, Yan Wang. Development status of diabetes nurse specialists in China [J]. Nursing Research, 2010, (27): 2449-2450.

25 Sun Zhenqiu. Comprehensive evaluation method of medicine and its application $[\mathrm{M}]$. Beijing: Chemical Industry Press, 2006:40.

26 Fan Luo, Xi Shuhua. Study on the construction of core competency evaluation index system for emergency specialized nurses [J]. Chinese Journal of Nursing, 2011, (02): 144-147.

27 Binhai Li, Junzhen Liu. Analysis on nurses' job stress, satisfaction and related factors [J]. Soft Science of Health, 2009, (01): 36-38.

28 Huang Junyao, He Qian. Analysis and suggestion on health human resources in the hospital [J]. 2009, (01): 126-127.

29 Wu Beiwen. Analysis and actuality in nursing research papers' writing and publishing [J]. Chinese Journal of Nursing, 2005, (05): 329-331.

30 Qiao Anhua, Xi Shuhua. A review on critical care nurse specialist certification and training [J]. Journal of Nursing Science, 2011, (02): 90-93.

31 Shang Linping, Xue Ping. Theoretical probe into carrying out specialist nurse certification system in China [J]. Nursing Research, 2008, (36): 3291-3292.

The first round of expert consultation questionnaire was formed based on literature review and expert interviews. The questionnaire contains three parts: the basic information of the expert, the text of the questionnaire comprising of the importance of indicators and the recommended modification by the expert as well as the familiarity of the expert with the question and the main basis for the expert to judge. The importance of indicators is based on the Likert scoring method, which is from very important to unimportant ( 1 - 5 points, respectively) [6]. Experts' familiarity with various indicators is divided into 5 levels: unfamiliar, not very familiar, general, relatively familiar, very familiar. Three rounds of questionnaires were distributed and received by email. 


\subsection{Statistical Methods}

The results were processed and analyzed by Microsoft Excel 2003 and SPSS17.0 to establish a database. The questionnaire response rate (\%) is used to reflect the enthusiasm of experts. The degree of coordination of expert opinions is expressed by the coefficient of variation $(\mathrm{Vj})$ of the evaluation results of various indicators and the Kendall's W coefficient of expert opinions and its significance test, where $\mathrm{Vj}$ represents the degree of fluctuation of the relative importance of the indicators, and the smaller the $\mathrm{Vj}$, the higher degree of coordination of expert opinions; The coordination coefficient $(\mathrm{W})$ ranging between 0 - 1 is used to test whether the opinions of experts on the indicators are consistent, the larger the value, the higher the coordination of the opinions of the experts. Significance test was performed on $\mathrm{W}$, if $\mathrm{P}<0.05$, it means that the experts have consistent scores on the indicators, indicating the results are desirable. The selection of research indicators is based on the criteria of satisfying both the mean value of importance value $>3.50$ and the coefficient of variation $\leq 0.25$. At the same time, combined with expert opinions, the indicators are screened by the collective review of the research team.

\section{Results}

\subsection{Basic Situation of Consulting Experts}

A total of 30 consulting experts participated, 17 of them aged 40 - 49 years old, accounting for $56.7 \%$. $90 \%$ of the experts had more than 20 -year working experience and had professional titles as deputy senior or higher. All of them had bachelor's degree or above including 11 professors (36.7\%). There were 15 experts major in clinical nursing (50\%) and 8 experts major in nursing management (26.7\%). Except for one from nursing colleges, the remaining 29 were from the Class A First Class Hospitals.

\subsection{The Questionnaire Recall Situation}

30 questionnaires were distributed each round, and the first round had the effective response rate $100 \%$; the second round, $86.7 \%$; the third round, $100 \%$.

\subsection{The Degree of Authority of Experts}

The degree of expert authority is reflected by the basis of experts' judgment on indicators and the familiarity of experts with indicators [7] [8] [9]. The average authoritative degree of experts in three rounds of consultation were $0.77-0.94$, $0.87,0.87$, respectively. It is generally considered that the degree of expert authority $\geq 0.7$ is acceptable [7]. Thus, the degree of expert authority in this study is relatively high.

\subsection{The Degree of Concentration of Expert Opinions}

The degree of concentration of expert opinions is expressed by the mean and standard deviation of importance assignment. The larger the mean, the more 
important the indicator is. The average values of the indicators in the three rounds of investigation were: $3.38-4.93,2.67-5.00,2.90-5.00$; and corresponding standard deviations were: $0.13-0.91,0.10-1.06,0.00-1.01$, respectively.

\subsection{Degree of Coordination of Expert Opinions}

After three rounds of consultation, the coefficient of variation of the third round of index assignment was $0.00-0.38$. The Kendall harmony coefficients $\mathrm{W}$ of experts in the three rounds of consultation were $0.366,0.374$, and 0.382 , respectively, and the significance test $\mathrm{P}<0.01$ indicated that the experts' opinions were well coordinated, and the results were desirable.

\subsection{Expert Consultation Results}

According to the selection criteria of the indicators and discussion by the research group, the indicators that failed both directions were deleted, and the indicators that failed one way were included in the next round of continued discussion. Due to space limitations, only the first two rounds of results were attached (Table 2).

\section{Discussion}

\subsection{Representativeness of Experts and Reliability of Prediction}

The selection of experts plays a key role in the Delphi method. In the study, we fully considered the professional representativeness, academic authority and geographical representation of experts. The selected experts include East China, West China, South China, North China, and Central China; their research areas include clinical nursing, nursing management, nursing education, community nursing and clinical medicine. The experts have a high level of knowledge and years of working experience in their professional fields. Many experts serve as Master or $\mathrm{PhD}$ supervisor. Moreover, the average authoritative coefficient, coordination coefficient and consistency of experts are relatively high; therefore, the representativeness and predictability of experts in this study are satisfied.

\subsection{Analysis of the Evaluation Index System for the First Certification of Diabetes Specialist Nurses}

Diabetes specialist nurses are nursing experts, and thus it requires that they should have certain professional abilities. Educational background and professional title are important factors that reflect the theoretical knowledge level and clinical professional skills of clinical nurses [8]. The years of working experience as a diabetes specialist can indirectly reflect the accumulated experience of the diabetes specialist nurses. The computer skill is a necessary part of the knowledge structure of expert talents. Nursing scientific research is an important means to promote the development of nursing science and to improve the quality of clinical nursing [9] [10] [11]. Specialized nurses conduct evidence-based 
Table 2. Mean value and coefficient of variation of the first and second round evaluation indicators.

\begin{tabular}{|c|c|c|c|c|}
\hline \multirow{3}{*}{ Indicators } & \multicolumn{2}{|c|}{ First round } & \multicolumn{2}{|c|}{ Second round } \\
\hline & Importance score & Coefficient of variation & Importance score & Coefficient of variation \\
\hline & $\bar{x} \pm s$ & $\mathrm{Vj}$ & $\bar{x} \pm s$ & $\mathrm{Vj}$ \\
\hline J1 Nurse practice certificate & $4.93 \pm 0.26$ & 0.05 & $5.00 \pm 0.00$ & 0.00 \\
\hline J2 Age & $\star 3.38 \pm 0.98$ & ${ }^{\star} 0.29$ & - & - \\
\hline J3 Education and degree & $3.97 \pm 0.73$ & 0.18 & $3.76 \pm 0.62$ & 0.17 \\
\hline J4 Job title & $3.76 \pm 0.79$ & 0.21 & $3.67 \pm 0.80$ & 0.22 \\
\hline J5 Diabetes specialist working years & $4.72 \pm 0.53$ & 0.11 & $4.43 \pm 0.75$ & 0.17 \\
\hline J6 Further study experience & $4.07 \pm 0.96$ & 0.24 & $4.00 \pm 0.89$ & 0.22 \\
\hline $\begin{array}{l}\text { J7 Annual paper published in recent } \\
5 \text { years (above statistic sources) }\end{array}$ & $3.66 \pm 0.97$ & ${ }^{\star} 0.27$ & $3.58 \pm 0.98$ & ${ }^{\star} 0.26$ \\
\hline J8 Scientific achievement & $3.62 \pm 0.94$ & ${ }^{\star} 0.26$ & $\star 2.90 \pm 1.09$ & ${ }^{\star} 0.38$ \\
\hline J9 Funded research & $3.65 \pm 0.95$ & ${ }^{\star} 0.26$ & $3.54 \pm 0.85$ & ${ }^{\star} 0.27$ \\
\hline J10 English proficiency & $3.62 \pm 1.05$ & ${ }^{\star} 0.27$ & $3.59 \pm 0.90$ & ${ }^{\star} 0.26$ \\
\hline J11 Computer skill & $3.79 \pm 0.90$ & 0.24 & $3.62 \pm 0.92$ & 0.25 \\
\hline J12 Continuing education credits & $3.69 \pm 1.17$ & ${ }^{\star} 0.32$ & $\star 3.41 \pm 0.26$ & ${ }^{\star} 0.30$ \\
\hline J13 Expert recommendation & $3.59 \pm 1.09$ & ${ }^{\star} 0.30$ & $3.71 \pm 0.26$ & ${ }^{\star} 0.26$ \\
\hline I Professional attitude & $4.93 \pm 0.26$ & 0.05 & $4.95 \pm 0.22$ & 0.03 \\
\hline II Service awareness & $4.93 \pm 0.26$ & 0.05 & $4.86 \pm 0.36$ & 0.07 \\
\hline II Professionalism & $4.83 \pm 0.38$ & 0.08 & $4.90 \pm 0.30$ & 0.06 \\
\hline II Team spirit & $4.76 \pm 0.44$ & 0.09 & $4.90 \pm 0.30$ & 0.06 \\
\hline II Enterprising spirit & $4.55 \pm 0.51$ & 0.11 & $4.71 \pm 0.46$ & 0.10 \\
\hline I Professional knowledge & $4.90 \pm 0.31$ & 0.06 & $4.88 \pm 0.41$ & 0.03 \\
\hline II Basic knowledge & $4.72 \pm 0.45$ & 0.10 & $4.95 \pm 0.22$ & 0.04 \\
\hline II Specialist knowledge & $4.90 \pm 0.31$ & 0.06 & $4.95 \pm 0.22$ & 0.04 \\
\hline $\begin{array}{l}\text { II Humanities and social sciences } \\
\text { and other related knowledge }\end{array}$ & $4.10 \pm 0.86$ & 0.21 & $4.48 \pm 0.75$ & 0.17 \\
\hline I Specialist technology & $4.86 \pm 0.44$ & 0.09 & $4.76 \pm 0.51$ & 0.04 \\
\hline II Nursing assessment technology & $4.76 \pm 0.44$ & 0.09 & $4.76 \pm 0.44$ & 0.09 \\
\hline II Nursing implementation technology & $4.79 \pm 0.41$ & 0.09 & $4.86 \pm 0.36$ & 0.07 \\
\hline II Specialist technical cooperation & $4.55 \pm 0.69$ & 0.14 & $4.71 \pm 0.56$ & 0.12 \\
\hline II Instrumentation technology & $4.55 \pm 0.63$ & 0.15 & $4.52 \pm 0.60$ & 0.13 \\
\hline I Core capabilities & $4.69 \pm 0.54$ & 0.12 & $4.72 \pm 0.45$ & 0.09 \\
\hline II Direct patient caring & $4.69 \pm 0.54$ & 0.12 & $4.86 \pm 0.36$ & 0.07 \\
\hline II Scientific research & $4.00 \pm 0.89$ & 0.22 & $4.86 \pm 0.48$ & 0.10 \\
\hline II Nursing management & $3.90 \pm 0.86$ & 0.22 & $4.10 \pm 0.07$ & 0.17 \\
\hline II Nursing education & $4.69 \pm 0.54$ & 0.54 & $3.86 \pm 0.79$ & 0.21 \\
\hline II Consultation & $4.52 \pm 0.63$ & 0.14 & $4.57 \pm 0.68$ & 0.15 \\
\hline II Ethical decision-making & $4.10 \pm 0.90$ & 0.22 & $4.24 \pm 1.04$ & 0.25 \\
\hline I Personal qualities & $4.31 \pm 0.76$ & 0.18 & $4.43 \pm 0.54$ & 0.12 \\
\hline II Physical fitness & $4.34 \pm 0.67$ & 0.15 & $4.57 \pm 0.51$ & 0.11 \\
\hline II Psychological health & $4.41 \pm 0.68$ & 0.15 & $4.62 \pm 0.50$ & 0.11 \\
\hline
\end{tabular}

Note: ${ }^{*}$ indicates that it does not meet the criteria for index screening. 
nursing research on new evidence found to continuously improve nursing practice [12]. However, according to the actual situation in China, the overall English level and scientific research level are limited. Even graduated from the nursing department, they have difficulties in communication in English resulting in that they can only obtain the latest foreign knowledge and information indirectly [13]. Thus, treating "Funded research" and "English proficiency" as fundamental indicators is not desirable, but in view of their importance, we decided to include the "annual average paper publication status", which is relatively easier, and the "English proficiency" is listed as one of the first-level indicators.

The construction of this research indicator framework is guided by the "Attitude Skill Knowledge" (ASK) theory. The ASK theory [14] [15] was proposed by professor Mayo from Harvard University in the 1860s and he pointed out that there is a progressive relationship among knowledge, attitudes and skills, in which knowledge is the foundation of skills; attitude is the motivation to acquire skills, and acquisition of skills is the goal. The first-level indicators of this study not only cover professional attitudes, professional knowledge, professional skills, and core competencies, but also consider personal characteristics; in the second-level indicators, there are specific requirements for each item, which can be used to systematically and comprehensively evaluate diabetes specialist nurses. In terms of professional attitude, nursing is the most humanized profession. Only people with love and service consciousness can be qualified for this noble profession. In terms of professional knowledge, diabetes specialist nurses are nursing experts in the field of diabetes, and they are required not only to master precise and specialized nursing theory, basic knowledge, and specialist knowledge, but also to be familiar with the frontier knowledge in the field of diabetes, health policies, organizational management, health economics and social sciences. IN terms of professional technology, a diabetes specialist nurse should not only master the nursing skills of this specialty, but also master the use of diabetes related instruments and the skills of cooperation with other medical personnel to provide systematic, comprehensive and holistic care for patients.

In terms of core competence, in order to enable diabetes specialist nurses to be competent for different tasks, including disease prevention, health promotion, and nursing of acute and chronic diseases, it is necessary to cultivate the professional attitude, professional knowledge and technology of diabetes specialist nurses. As for personal characteristics, nursing tasks are heavy, and only a nurse with a healthy body can be competent. When dealing with pressure from work and life, they should reasonably control their emotions, adjust themselves, fully understand themselves and make appropriate evaluations of themselves.

\subsection{Suggestions on the Implementation of the First Certification Evaluation Index System for Diabetes Specialist Nurses}

1) It is necessary to establish relevant systems and legal regulations for the certification of diabetes specialist nurses. At present, the current status of the practice of diabetes specialist nurses in our country is neither compliant nor 
rule-based [16]. Only by guaranteeing the legal certification of diabetic specialist nurses and having the law to be able to guarantee the healthy operation of the diabetic nurse certification mechanism, should the government be given full play to standardize the management of diabetic nurses and ensure the quality and control of diabetic nurses.

2) It is also necessary to encourage the establishment of statutory social intermediary institutions, which are entrusted or authorized by the government to certify diabetes specialist nurses and other specialist nurses. It is an independent non-profit organization between the government, society and medical units. The organization can be scientific groups or professional associations. The legal social intermediary organization can guarantee the objectivity and fairness of the certification and evaluation of diabetes nurses.

3) It is recommended to formulate the first certification procedure for diabetic specialist nurses according to the following procedures: a) An individual submits a certification application to the relevant certification organization with corresponding application materials; b) The certification organization conducts the qualification review of the applicant according to the certification standards; c) Applicants are required to conduct theoretical assessment; d) Interview; e) Comprehensive evaluation of clinical ability; f) Issue of diabetes specialist nurse certificate. Standardized first-time certification procedure of diabetes specialty nurses can make the certification of nurses more convenient and standardized.

The government should strengthen the selection of certified experts, closely connect academic experts. In additional to management authorities and industry, other parties should participate and cooperate with one another in order to give full play to their respective advantages. To strengthen the combination of certification and the practice registration system, we must not only allow practice registration to promote the development of professional certification, but also reflect that certification is the basis for the effective implementation of the practice registration system.

\section{Conflicts of Interest}

The authors declare no conflicts of interest regarding the publication of this paper.

\section{References}

[1] International Diabetes Federation (2007) Diabetes Atlas. 3rd Edition, International Diabetes Federation, Brussels.

[2] Yang, W., Lu, J., Weng, J., et al. (2010) Prevalence of Diabetes among Men and women in China. The New England Journal of Medicine, 362, 1090-1101. https://doi.org/10.1056/NEJMoa0908292

[3] Wu, L.P., Li, H.P. and Zhao, M. (2011) Research of Qualifications of Diabetes Specialized Nurses. Journal of Nursing, No. 16, 8-10.

[4] Wu, L.P., Li, H.P., Zhao, M. and Fang, X.P. (2011) Status Quo of Diabetes Specialist Nurses Cultivation. Journal of Nursing Science, No. 11, 87-90. 
[5] Jin, R.H., Zheng, J. and Wang, Y. (2010) Development Status of Diabetes Nurse Specialists in China. Chinese Nursing Research, No. 27, 2449-2450.

[6] Chen, X.R. (1993) Introducing a Good Book-Statistical Analysis in Investigation and Research. Application of Statistics and Management, No. 1, 42-43.

[7] Zhou, H.X. and Zhu, J.C. (2007) Evaluation System for Clinical Competence of Nursing Undergraduates. Nurs J Chin PLA, No. 12, 4-7.

[8] Li, B.H. and Liu, J.Z. (2009) Analysis on Nurses' Job Stress, Satisfaction and Related Factors. Soft Science of Health, No. 1, 36-38.

[9] Zhong, Y.J. and Duan, M.J. (2008) A Survey of the Status Quo of Cognition of College Nursing Students on Evidence-Based Nursing. Chinese Nursing Research, No. 35, 3211-3213.

[10] Cao, H.M. and Chen, X.Y. (2009) Probe into Nursing Scientific Research Practice and Management Thinking. Chinese Nursing Research, No. 6, 533-535.

[11] Beiwen, W. (2005) Analysis and Actuality in Nursing Research Papers' Writing and Publishing. Chinese Journal of Nursing, No. 5, 329-331.

[12] Hamric A B SJA, Hanson CM. (2009) Advanced Practice Nursing: An Integrative Approach. Saunders, USA.

[13] Zhang, B. and Sun, B.L. (2003) Challenges, Opportunities and Development Strategies Faced by Nursing Profession in Our Country after Joining in the WTO. Chinese Nursing Research, No. 7, 373-374.

[14] Heins Jr., H.C. (2006) A KAP (Knowledge-Attitude-Practice) Approach to the Regionalization of Perinatal Health. The Journal of the Arkansas Medical Society, 73, 229-234.

[15] Huang, J.H. (2002) Health Education. Fudan University Press, Shanghai, 3428-3492.

[16] Shang, L.P., Xu, J. and Xue, P. (2008) Theoretical Probe into Carrying out Specialist Nurse Certification System in China. Chinese Nursing Research, No. 36, 3291-3292. 